BMJ Nutrition,

Prevention \& Health

\section{Lifestyle medicine for type 2 diabetes: practice-based evidence for long-term efficacy of a multicomponent lifestyle intervention (Reverse Diabetes2 Now)}

To cite: Pot GK, BattjesFries MCE, Patijn ON, et al. Lifestyle medicine for type 2 diabetes: practice-based evidence for long-term efficacy of a multicomponent lifestyle intervention (Reverse Diabetes2 Now). BMJ Nutrition, Prevention \& Health 2020;3:e000081. doi:10.1136/ bmjnph-2020-000081

- Additional material is published online only. To view please visit the journal online (http://dx.doi.org/10.1136/ bmjnph-2020-000081).

For numbered affiliations see end of article.

Correspondence to Dr Gerda K Pot, Louis Bolk Instituut, Bunnik 3981 AJ, Netherlands; g.pot@louisbolk.nl

GKP and MCB-F contributed equally.

Received 6 April 2020 Revised 24 June 2020 Accepted 25 June 2020 Published Online First 18 August 2020
Check for updates

(C) Author(s) (or their employer(s)) 2020. Re-use permitted under CC BY-NC. No commercial re-use. See rights and permissions. Published by BMJ.

\section{ABSTRACT}

Introduction A wealth of evidence supports short-term efficacy of lifestyle interventions in type 2 diabetes (T2D). However, little is known about long-term effects of lifestyle interventions in real-life settings.

Methods This observational, single-arm study evaluated long-term impact of 'Voeding Leeft: Reverse-Diabetes2Now', a 6-month multicomponent lifestyle programme, on glycaemic control and glucose-lowering medication (GLmed) use, other T2D parameters and quality of life in 438 T2D participants at 6, 12, 18 and 24 months using paired sample t-tests, $\chi^{2}$ and generalised linear models. Results At 24 months, 234 participants provided information on GLmed and HbA1c ('responders'). 67\% of the responders used less GLmed, and $28 \%$ ceased all GLmed. Notably, $71 \%$ of insulin users at baseline $(n=47$ of 66 insulin users) were off insulin at 24 months. Mean $\mathrm{HbA1c}$ levels were similar at 24 months compared with baseline $(55.6 \pm 12.8$ vs. $56.3 \pm 10.5 \mathrm{mmol} / \mathrm{mol}, \mathrm{p}=0.43)$, but more responders had $\mathrm{HbA} 1 \mathrm{c}$ levels $\leq 53 \mathrm{mmol} / \mathrm{mol}$ at 24 months ( $53 \%$ vs $45 \%$ at baseline). Furthermore, triglyceride levels $(-0.34 \pm 1.02 \mathrm{mmol} / \mathrm{L}, p=0.004)$, body weight $(-7.0 \pm 6.8 \mathrm{~kg}, \mathrm{p}<0.001)$, waist circumference $(-7.9 \pm 8.2 \mathrm{~cm}, p<0.001)$, body mass index $(-2.4 \pm 2.3 \mathrm{~kg} /$ $\left.\mathrm{m}^{2}, \mathrm{p}<0.001\right)$ and total cholesterol/high-density lipoprotein $(\mathrm{HDL})$ ratio $(-0.22 \pm 1.24, \mathrm{p}=0.044)$ were lower, while HDL $(+0.17 \pm 0.53 \mathrm{mmol} / \mathrm{L}, \mathrm{p}<0.001)$ and low-density lipoprotein-cholesterol levels $(+0.18 \pm 1.06 \mathrm{mmol} / \mathrm{L}$, $p=0.040$ ) were slightly higher. No differences were observed in fasting glucose or total cholesterol levels. Quality of life and self-reported health significantly improved.

Conclusion This study indicates robust, durable real-life benefits of this lifestyle group programme after up to 24 months of follow-up, particularly in terms of medication use, body weight and quality of life in T2D patients.

\section{INTRODUCTION}

Type 2 diabetes (T2D) is a prototypical non-communicable chronic disease (NCD), emanating from gene-behaviour interactions. ${ }^{1} 2$ Unhealthy lifestyle factors, such as poor eating habits, physical inactivity, sleep deprivation and stress, contribute to the development of $\mathrm{NCDs}^{3-5}$ and increase mortality risk. ${ }^{6} 7$ Therefore, lifestyle modification should be a structural element of NCD treatment strategies. Although lifestyle intervention usually constitutes a component of the guidelines for clinical management of any NCD, current clinical practice primarily embraces drugs to ameliorate symptoms and prevent disease progression.

Several lifestyle intervention studies have shown promising effects in T2D patients. The DiRECT study $^{8}{ }^{9}$ and the VirtaHealth trial $^{1011}$ demonstrated a 46\%-64\% remission rate of $\mathrm{T} 2 \mathrm{D}$ after 2 years. However, both DiRECT (very low-calorie meal replacement) and Virta (nutritional ketosis) interventions require radical changes of food consumption. Several other studies, evaluating more modest changes in one or two lifestyle components, yielded long-term (9 months to 4 years) benefits in T2D as well. $^{12-14}$ Most lifestyle interventions to date are primarily focused on one or two aspects of lifestyle involved in the aetiology of T2D. However, fully effective lifestyle advice encompasses nutrition, physical activity, sleep and stress management. ${ }^{15}$ In addition, sustained behaviour change requires psychological support, for example cognitive behavioural support. ${ }^{16}$ In 2015, the Foundation Voeding Leeft developed a multicomponent lifestyle intervention for T2D ('Reverse-Diabetes2-Now' (RD2N)) to support T2D patients in their efforts to change their lifestyle to remedy their disease. $\mathrm{RD} 2 \mathrm{~N}$ is a 6-month group programme using biometric feedback for personalised advice pertaining to the full range of lifestyle factors involved in the T2D pathogenesis. It focuses on improving skills rather than just knowledge of all relevant lifestyle components. In a pilot study, RD2N improved glucose control and reduced GLmed use in 72 T2D 
patients. ${ }^{17}$ In this study, we report data of all participants who completed 24 months of follow-up.

\section{METHODS}

\section{Study population}

T2D patients who started their RD2N programme between January and December 2017 were enrolled in this study. Patients were included using a stepped-wedge design, with $\sim 20$ patients per group per location starting each month (a 'convenience sample'). Inclusion criteria for the RD2N programme were T2D diagnosis, age 18-75 years, body mass index (BMI) $25-41 \mathrm{~kg} / \mathrm{m}^{2}$, ability to speak Dutch fluently and motivation to take part in a lifestyle intervention programme. Moreover, all participants used glucose-lowering medication (GLmed) at baseline. Exclusion criteria were use of an insulin pump, serious co-morbidities, for example, severe form of chronic obstructive pulmonary disease (Gold III or IV), bariatric surgery, eating disorders, heart failure (classes 2-4) or kidney failure (estimated Glomerular Filtration Rate/ Modification of Diet in Renal Disease study equatione (eGFR/MDRD) <45 unit). Patients, as well as their physician, provided written informed consent.

\section{Lifestyle intervention program}

$\mathrm{RD} 2 \mathrm{~N}$ is a 6-month lifestyle intervention programme, extended by optional follow-up, to help T2D patients gain control over their disease by improving their health, nutrition and lifestyle skills ${ }^{17}$ (see Box 1 for main elements of programme). Nutritional advice entailed increased intake of unprocessed/whole or minimally processed foods, being low in high glycaemic carbohydrates and fitting with a Mediterranean food pattern. ${ }^{18}$ In addition, health and food literacy skills were increased by explaining the underlying pathophysiology of T2D in simple language and the effects of food on health, that is T2D is a disease with insulin resistance as most important feature and that the body cannot handle the intake of glucose very well. Moreover, information was provided to develop cooking skills, manage stress, tackle mental obstacles and implement physical activity routines. Participants were provided with 6-month intensive guidance by a multidisciplinary support team, including a dietitian, personal coach and nurse practitioner. To enhance effectiveness, partners/ family of participants were also actively involved in the process, ${ }^{19}$ and participants received instant feedback on

Box 1 Key success elements nutrition and lifestyle intervention programme

- Intense training/contact coaches/knowledge transfer explaining underlying causes of disease.

- Multidisciplinary (dietitian, personal coach and nurse practitioner).

- Involvement social environment and create support group.

- Nutritional advice: individual approach, not calorie restricting, fresh and unprocessed foods and three-meal approach. their progress, for example measuring their own blood glucose levels before and after meals. ${ }^{20} \mathrm{RD} 2 \mathrm{~N}$ started with 2-day group training on location. Subsequently, groups were invited for a 1-day follow-up meeting after 1, 3 and 6 months. Meanwhile, all groups were encouraged to keep in regular contact with each other and the support team, using a protected online community platform. ${ }^{19}$

\section{Study design and setting}

Researchers of the Louis Bolk Institute (the Netherlands) independently monitored the results of the RD2N programme, which was set-up and executed by personnel of Voeding Leeft. An observational, single-arm pretest and post-test design was used for this monitoring study. Recruitment of participants was executed by Voeding Leeft and was not part of this monitoring study. Data on primary outcome and most secondary outcome parameters at baseline were collected via the patients' physician. As participants became more aware of the importance of the outcome biomarkers in the course of the programme, they were asked to self-report them during follow-up. Data on secondary study outcomes at baseline and all study outcomes during follow-up were collected via online questionnaires. One week prior to the initiation of the programme and 1 week before the final meeting at 6 months, as well as at 12, 18 and 24 months of follow-up, participants received an email with a link to these questionnaires. To promote completeness of the data at 24 months, the support team actively approached participants. At 6 and 24 months of follow-up, data on the primary outcome parameters were complemented with data from Voeding Leeft.

\section{Primary outcome measures: GLmed and Hb1Ac values}

Baseline GLmed use was assessed by asking participants to report on the dose and frequency of their GLmed. GLmed use was classified as (0) no medication, (1) only metformin, (2) metformin and/or sulfonylurea (SU) derivative or (3) metformin and/or SU derivative and/or insulin. GLmed was prescribed according to the Dutch general practitioners (GPs) guideline for T2D treatment. ${ }^{21}$ HbA1c levels were measured as a usual component of routine physician follow-up. Participants self-reported their data to the investigators and/or to the data collection team at Voeding Leeft.

\section{Secondary outcome measures}

Secondary outcome measures included self-reported fasting blood glucose, height, weight, waist circumference and lipid profile (total cholesterol, high-density lipoprotein (HDL), low-density lipoprotein (LDL) and triglycerides). Participants were asked to report values as recently measured by their physician according to the Dutch GPs guideline standards ${ }^{21}$ to the data collection team at Voeding Leeft at baseline and to the investigators during follow-up. Perceived health and quality of life were assessed with a 10-point Likert scale. The validated 'Checklist Individual Strength' questionnaire ${ }^{22}$ was used 
to assess fatigue during the past 2 weeks on a 7-point scale (ranging from (not) to (very applicable)). Programme adherence was assessed with a 5-point Likert scale. Furthermore, at baseline, information was collected on date of birth, sex, education level and family structure at home.

\section{Statistical analyses}

Descriptive analyses were conducted to describe participants' socio-demographic characteristics. Data were described as means $\pm \mathrm{SD}$, if they were normally distributed, or $\mathrm{n}$ (percentage). Next, paired sample t-tests were conducted to evaluate the effects of the RD2N programme on change in each measured parameter (follow-up vs baseline) and $\chi^{2}$ tests were used for categorical variables. Repeated measures analyses using generalised linear models were conducted to evaluate the effects of the RD2N programme on changes in each measured numerical parameter using data available at all time points. Furthermore, at 24 months analyses were stratified using three predefined subgroups: (1) HbAlc level $\leq 53 \mathrm{mmol} / \mathrm{mol}$ ('low HbAlc starters') or $>53 \mathrm{mmol}$ / mol ('high HbAlc starters'), (2) use of GLmed at baseline (categorised into two main groups: category 1 (metformin only, termed 'low GLmed') vs categories 2 and 3 (ie, SU derivatives and/or insulin, termed 'high GLmed')) and (3) education level as proxy for socioeconomic status (SES) as information on income was not available. These subgroups were predefined, as we were interested to know if any of them were more likely to respond to the intervention. People with bad metabolic control tend to respond better to (any) treatment for T2D and people with high SES are usually more amenable to lifestyle advice, and it would be useful for broad clinical implementation of the intervention to know if RD2N is particularly effective in patients using less or more medication. Results were interpreted as statistically significant when $\mathrm{p}<0.05$ (two-sided) and SPSS (V.24.0) was used to conduct statistical analyses. Data were analysed using a per-protocol approach reporting data of those who provided data on the study outcome parameters at both baseline and 24 months (='responders').

\section{RESULTS}

Subjects

Of note, 438 participants, in 23 groups of 15-20 patients each were included in this study. Of these, 234 participants (53\%) provided data on HbA1c and GLmed at baseline as well as 24 months, the 'responders'. The baseline characteristics of the responders $(n=234)$ were similar to those of all participants who started the programme $(n=438)$ (table 1). Due to missing or invalid answers, data on secondary outcomes at 24 months are presented for fewer participants, varying from 111 to 195 of the 438 participants $(25 \%-45 \%)$ per outcome measure. The responders' age ranged from 22 to 75 years, and was $61.3 \pm 8.5$ years on average (table 1 ). Just over half the responders were men $(53 \%)$ and $54 \%$ had low or middle education.

Table 1 Demographic characteristics at baseline of all participants $(n=438)$ and of those who provided data on $\mathrm{HbA1c}$ and GLmed use at both baseline and 24 months ('responders', $n=234$ )

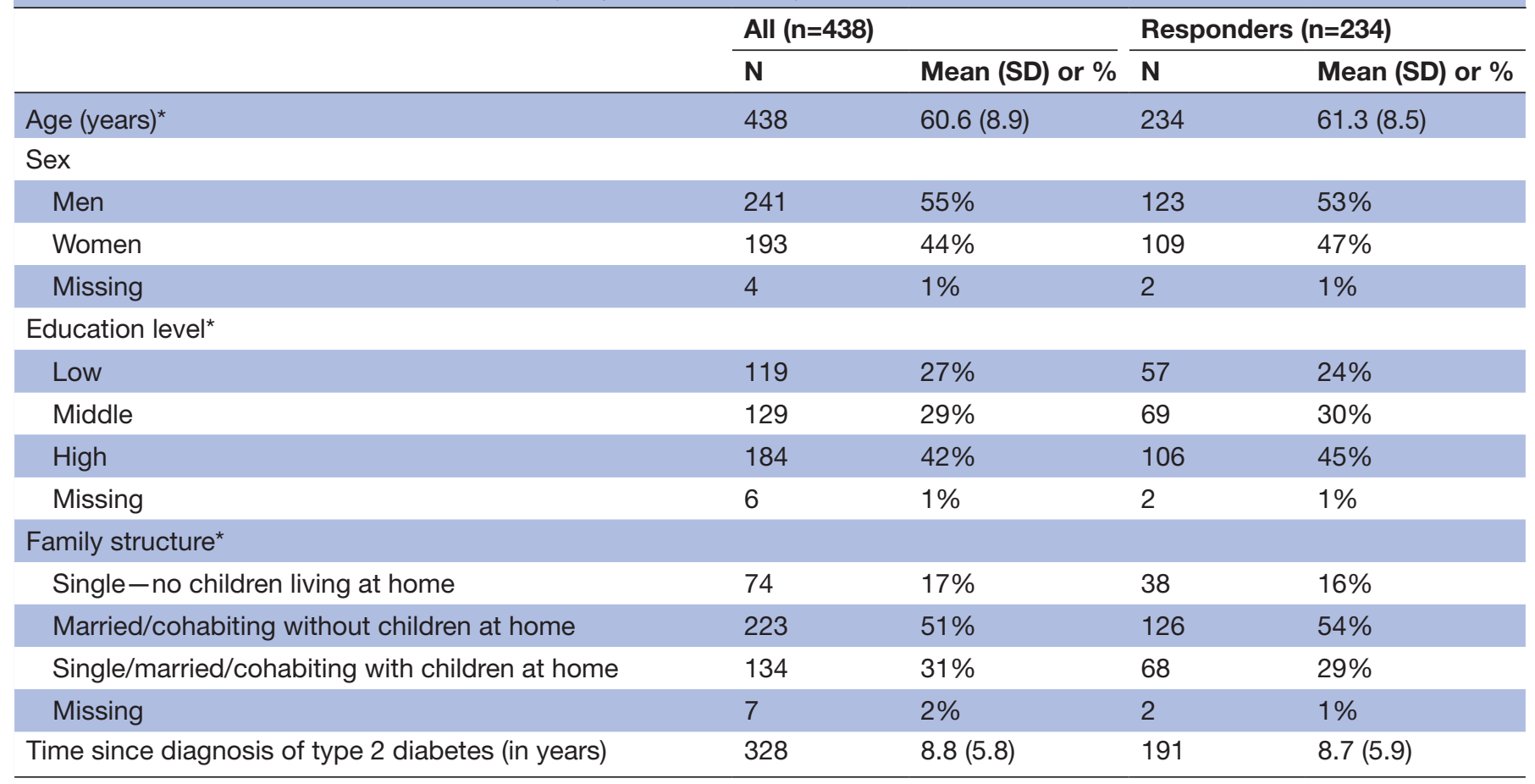

*Missing for some responders.

GLmed, glucose-lowering medication. 


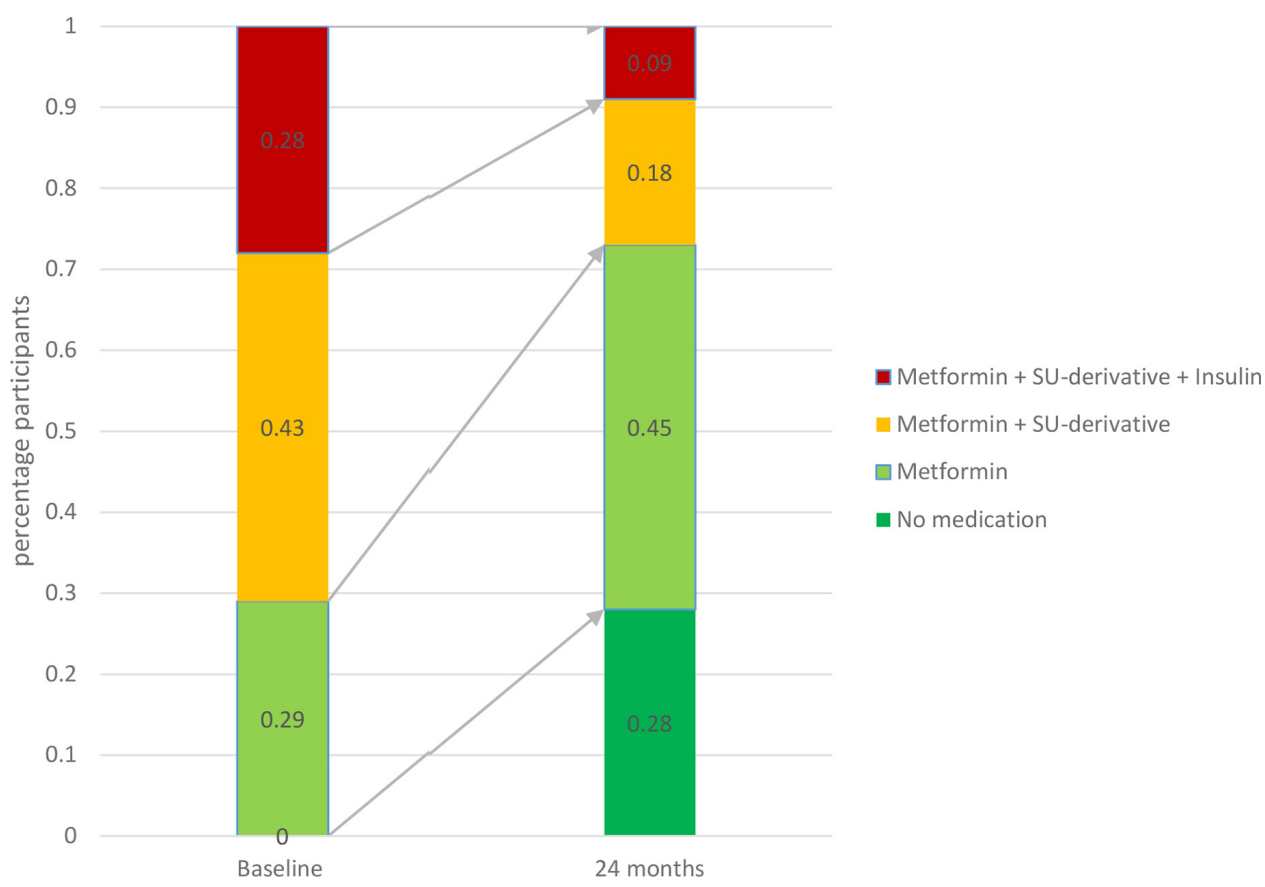

Figure 1 Percentage of responders in various GLmed categories at baseline and at 24 months $(n=234)$. SU, sulfonylurea.

\section{Primary outcome measures}

GLmed use

All responders used GLmed at baseline, as GLmed use was an inclusion criterion of RD2N. GLmed use was less in $67 \%$ of responders after 24 months. Indeed, $28 \%$ of responders ceased all GLmed use, and $71 \%$ of responders using insulin at baseline was off insulin therapy at 24 months. In $2 \%$ of responders GLmed actually increased, and in $31 \%$ it remained stable as compared with baseline (figure 1).

Subgroup analyses showed that a similar fraction of responders with low (68\%) versus high $(66 \%)$ baseline HbA1c levels was able to lower their GLmed. However, the percentage of responders who were able to cease their GLmed use was higher in those with low baseline HbA1c levels (40\%) compared with those with high baseline HbA1c levels (18\%; online supplementary table 1). For different education-level subgroups, we found that the percentage of responders who were able to lower or cease their GLmed use at 24 months was highest for those in the low education group $(79 \%$ and $30 \%$ for low vs $58 \%$ and $25 \%$ for middle education and $68 \%$ and $29 \%$ in high education; online supplementary table 1 ). We did not perform subgroup analyses for baseline GLmed here, as it goes without saying that the possibilities for stopping medication are greater in people who use more of it.

\section{HbA1c levels}

HbA1c levels initially declined, but gradually increased over time (figure 2). HbAlc levels at 24 months were not different from baseline $(-0.67 \pm 12.9 \mathrm{mmol} / \mathrm{mol}$, $\mathrm{p}=0.430$ ). At 24 months, $53 \%$ of responders had HbA1c levels $\leq 53 \mathrm{mmol} / \mathrm{mol}$, compared with $45 \%$ at baseline.

After stratification into predefined subgroups (online supplementary table 2), we found that HbA1c levels were significantly lower at 24 months compared with baseline in responders who had high baseline HbAlc levels $(-4.7 \pm 13.9 \mathrm{mmol} / \mathrm{mol}, \mathrm{p}$ value $<0.001)$. In contrast, HbAlc levels increased in those who had an HbAlc $\leq 53 \mathrm{mmol} / \mathrm{mol}$ at baseline $(4.2 \pm 9.5 \mathrm{mmol} / \mathrm{mol}$, p value $<0.001)$. However, GLmed use declined substantially in the latter group, while HbAlc levels remained below the target value defined in treatment guidelines (ie, $53 \mathrm{mmol} /$ mol). Subgroup analyses in low or high GLmed showed that only responders using just metformin at baseline had a significant decline in HbAlc levels $(-3.6 \pm 9.3 \mathrm{mmol} /$ mol, $\mathrm{p}=0.002$ vs $0.5 \pm 13.9, \mathrm{p}=0.62)$. We found no differences in effects on HbAlc between different education subgroups.

\section{Glucose control and GLmed use combined}

Forty-four per cent of responders reported the use of less medication and a lower HbA1c, $42 \%$ reported less medication or a lower HbAlc, leaving $14 \%$ reporting more medication or a higher HbAlc. Thus, the vast majority $(86 \%)$ of responders reported at least one benefit of the intervention in terms of glucose control.

\section{Secondary outcome measures}

\section{Other T2D biomarkers and health parameters}

At 24 months, responders had significantly lower triglyceride levels $(-0.34 \pm 1.02 \mathrm{mmol} / \mathrm{L}, \mathrm{p}=0.004)$, total cholesterol/HDL ratio $(-0.22 \pm 1.24 \mathrm{mmol} / \mathrm{L}, \mathrm{p}=0.044)$, body weight $(-7.01 \pm 6.8 \mathrm{~kg}, \mathrm{p}<0.001)$, BMI $(-2.36 \pm 2.28 \mathrm{~kg} /$ $\left.\mathrm{m}^{2}, \mathrm{p}<0.001\right)$ and waist circumference $(-7.9 \pm 8.2 \mathrm{~cm}$, $\mathrm{p}<0.001)$, and higher HDL $(0.17 \pm 0.53 \mathrm{mmol} / \mathrm{L}, \mathrm{p}<0.001)$ and LDL levels $(0.18 \pm 1.06 \mathrm{mmol} / \mathrm{L}, \mathrm{p}=0.044)$ (table 2). No statistical significant differences were found for fasting glucose and total cholesterol at 24 months compared with baseline. Also taking into account measurements at 6, 12 


\section{Change in HbA1c levels over time}

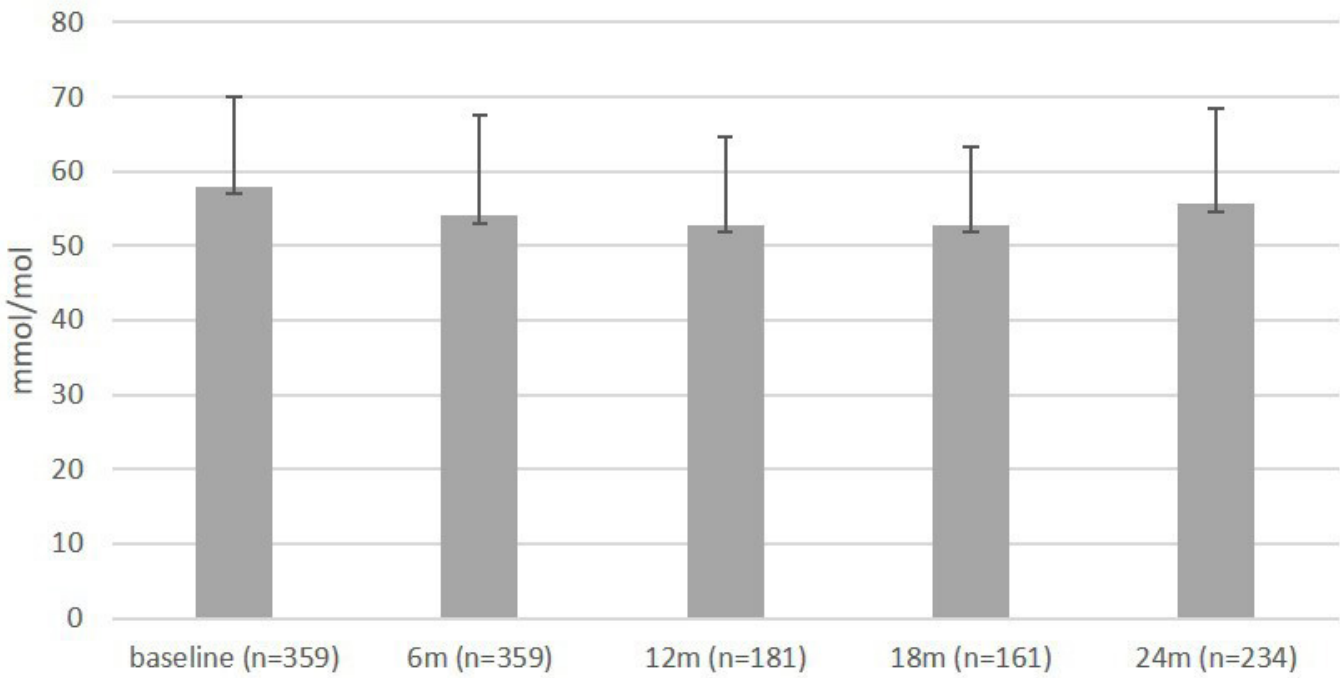

Figure 2 Mean HbA1c levels (in $\mathrm{mmol} / \mathrm{mol}$ ) over time atbaseline, 6, 12, 18 and 24 months. The number of participants differs per timepoint, as these are the participants who provided data on HbA1c at both baseline and follow-up.

and 18 months we found similar results, except that significant changes in HDL, total cholesterol/HDL ratio and LDL at 24 months were not statistically significant, but it should be noted that numbers of responders included in the repeated measures analyses were lower.

Subgroup analyses showed similar findings for responders with low or high baseline HbA1c levels, except for triglycerides, which declined significantly only in responders with high baseline HbA1c $(\mathrm{p}<0.001$; online supplementary table 3A). Those with low baseline GLmed had similar results as those with high baseline GLmed (online supplementary table 3B). Interestingly, in regards to education level, we observed most prominent changes of HDL, total cholesterol/HDL ratio and triglycerides in those with low education level (online supplementary table 3C).

Table 2 Secondary outcomes: mean scores and changes of health parameters, self-perceived health, quality of life and fatigue at baseline and 24 months (of $n=438$ )

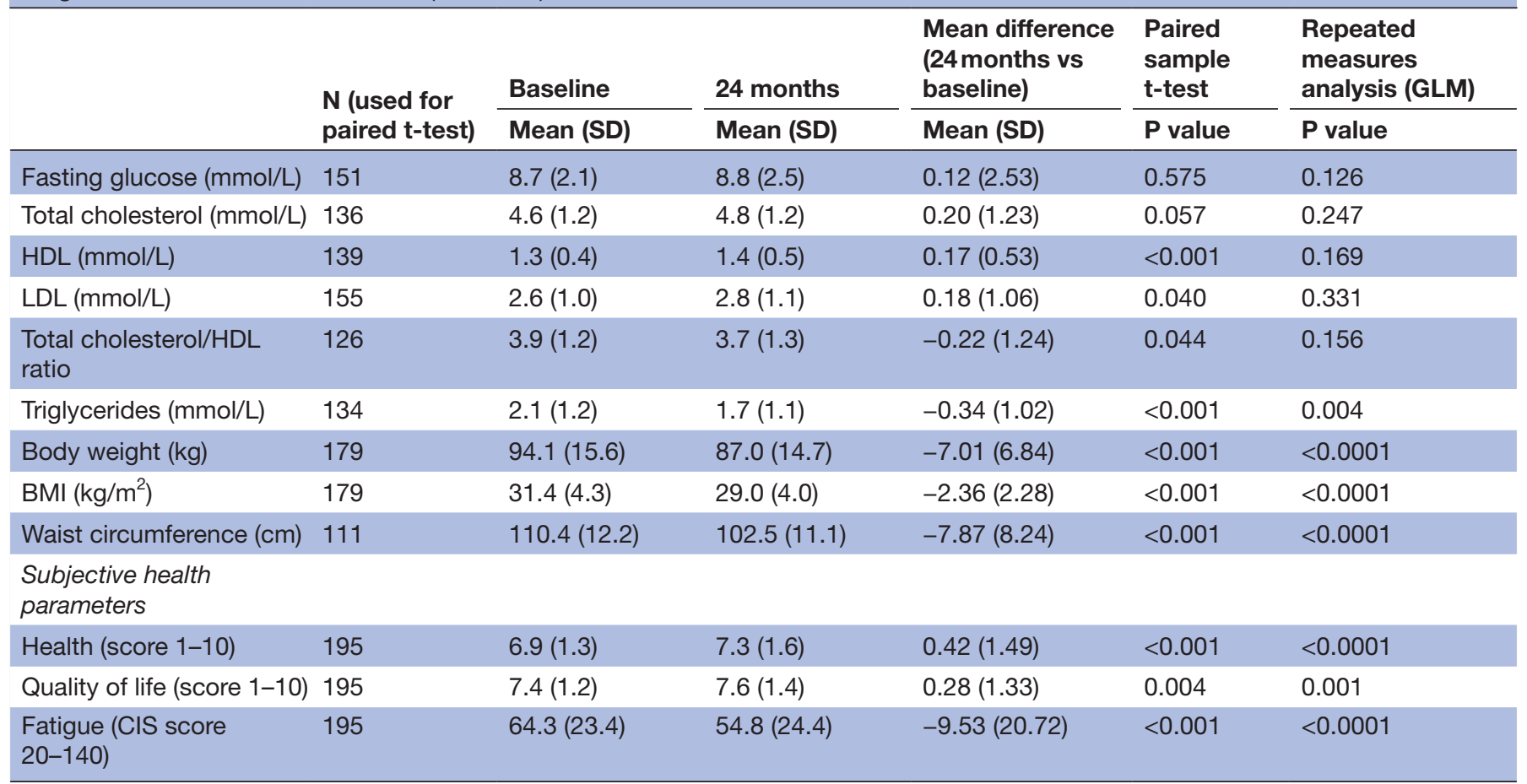

BMI, body mass index; CIS, Checklist Individual Strength; GLM, generalised linear models; HDL, high-density lipoproteins; LDL, lowdensity lipoproteins. 


\section{Subjective health parameters}

Both self-perceived health and quality of life of responders were significantly higher at 24 months compared with baseline: self-perceived health increased by $0.4 \pm 1.5$ (scale $1-10) \quad(\mathrm{p}<0.001)$ and quality of life increased by $0.3 \pm 1.3$ (scale $1-10) \quad(p=0.001)$. In addition, scores for fatigue were significantly lower at 24 months compared with baseline $(-9.5 \pm 20.7$ at a scale of $20-140, \mathrm{p}<0.001)$. Results remained similar when performing repeated measures analyses also including information at 6,12 and 18 months.

Subgroup analyses yielded similar results for those responders with low or high baseline HbA1c levels (online supplementary table 3A), except for quality of life, which only improved in those with high baseline HbAlc levels $(p=0.012)$. Self-perceived health, quality of life and fatigue improved significantly only in responders in the high GLmed category at baseline (online supplementary table 3B). With regards to education level, self-reported health, quality of life and fatigue all improved significantly in those with low education level, whereas simply quality of life and fatigue improved in middle education level and only fatigue in those with a high education level (online supplementary table $3 \mathrm{C}$ ).

\section{Programme adherence and appreciation}

At 24 months, $90 \%$ of responders reported to almost fully adhere to the nutrition guidelines for breakfast, $81 \%$ for lunch, $79 \%$ for dinner, $53 \%$ for snacks and $83 \%$ for drinks. Fifty-three per cent of responders indicated that they did not find it difficult to adhere to the programme guidelines, but $41 \%$ of the responders found it difficult to adhere to the programme guidelines at social events. Furthermore, $67 \%$ reported to be (very) motivated to continue adherence to the guidelines, and $92 \%$ of responders gave a score of $\geq 8$ (scale 1-10) to recommend this programme to friends or family. There were no differences in recommending this programme to others in relation to education level ( $78 \%$ for low education, $80 \%$ for middle and $77 \%$ for high), although more responders with low education level indicated that eating according to the recommendations was (very) expensive (39\% for low vs $34 \%$ for middle and $23 \%$ for high education level) and (very) difficult to adhere to the programme guidelines ( $31 \%$ for low vs $27 \%$ for middle and $18 \%$ for high education level).

\section{DISCUSSION}

The results of this study showed that a 6-month multidisciplinary group programme designed to promote health literacy and lifestyle skills improves clinical parameters as well as quality of life in a substantial percentage of T2D patients after up to 24 months of follow-up. Indeed, the vast majority of the responders reported to use less GLmed as compared with baseline. Moreover, $44 \%$ of responders reported to use less medication and a lower HbA1c, $42 \%$ reported the use of less medication or a lower HbA1c, leaving $18 \%$ to report a higher HbA1c or the use of more medication. In addition, their body weight and waist circumference declined, as well as their serum triglyceride levels and total cholesterol/HDL cholesterol ratio. Moreover, their quality of life, self-perceived health and fatigue were all significantly improved at $24 \mathrm{~m}$.

In a recent pilot study evaluating the effects of RD2N treatment, $62 \%$ of responders reduced GLmed at 6 months. ${ }^{17}$ The present study confirms that the treatment effectively sustains this benefit over 24 months, since two-thirds (67\%) of all responders reduced their GLmed by that time. Indeed, 71\% (47 of 66) of responders who used insulin at baseline were off insulin therapy at 24 months. These effects are of obvious clinical and economic benefit, even in the context of the non-significant reduction of $\mathrm{HbAlc}$ that was observed during the same follow-up period. Moreover, RD2N also seemed to bring about sustainable benefits in terms of other health parameters, including various components of the metabolic syndrome, as well as improvements in self-perceived health, quality of life and fatigue. It is difficult, if not impossible, to ascertain which elements of the programme are responsible for these durable effects. However, we suspect that the multidisciplinary approach, focusing on a broad spectrum of lifestyle skills rather than health literacy alone, as well as provision of biofeedback information on the effects of the intervention were of critical importance.

Subgroup analyses revealed that HbA1c levels increased slightly in responders who had baseline HbA1c levels $\leq 53 \mathrm{mmol} / \mathrm{mol}$, while it declined in those with a baseline HbAlc $>53 \mathrm{mmol} / \mathrm{mol}$. However, GLmed use declined substantially in the former group (39\% stopped GLmed entirely), while HbAlc levels remained below target values according to clinical treatment guidelines. This means that RD2N treatment significantly reduced medication use to control blood glucose in people with wellcontrolled HbAlc to begin with. Surprisingly, responders with low HbA1c and GLmed use at baseline did less well in terms of subjective health parameters, perhaps because they were in better shape to begin with.

About one-third of the responders in the present study had a lower education level. Interestingly, they were most successful in terms of reversal after 6 months, but the difference between education-level groups disappeared at 24 months. We consider this an important finding, as it shows that the programme is at least equally effective across groups with different education levels in the long term. This goes against conventional wisdom, which consistently suspects people with a lower education level to be less accessible and responsive to lifestyle intervention. However, the fact that participation in the programme was (obviously) voluntarily reflects intrinsic motivation to change lifestyle, which equally applies to people with different education levels.

Several other lifestyle interventions have also shown promising results in the treatment of T2D. The DiRECT study and Virta trial reported impressive success after 
24 months of follow-up. ${ }^{911}$ However, these interventions appear to be a considerable burden on the willpower of people, perhaps rendering them less suitable for a significant percentage of patients. Moreover, they primarily focus on nutrition as a target of lifestyle modification, while other lifestyle factors such as stress, sleep and physical activity are also well known to contribute to the pathogenesis of T2D. ${ }^{23-26}$ These potential caveats do not mean that these interventions will turn out to be less useful in clinical practice. Indeed, it is increasingly recognised that the biological response to a lifestyle intervention (as well as the response to drugs) differs substantially between individuals. ${ }^{27}$ In addition, sustained reversal of T2D requires lifelong adherence to lifestyle measures, therefore it is of critical importance for the success of any lifestyle intervention that it fits as closely as possible with the patients' preferences. Some people undoubtedly prefer (intermittent) meal replacement to a more modest but structural modification of their daily diet. Others may like to focus on stress and physical activity rather than food. Thus, a broad variety of available effective interventions, offering distinct treatment options to patients, will benefit more people and it could well be possible that tackling a combination of lifestyle factors is key.

We report real-world data, which is a strength of our study, as it reflects the impact of RD2N in daily clinical practice and thus provides evidence for real-life robust results. However, data collection in everyday life is less well structured than in the context of a traditional clinical trial. The number of non-responders has been substantial in the present analyses (47\%), which probably biased the results since it is reasonable to suppose that less successful participants were more reluctant to respond to information requests.

Moreover, our analyses did not compare RD2N with another intervention, placebo and/or standard medical care. The lack of a control comparison hampers interpretation of the observations in terms of causality. However, application of the Bradford Hill criteria ${ }^{29}$ to our study suggests that a causal relationship between intervention and observed effects may be possible, as findings are biologically plausible and consistent over time. Also, we cannot be absolutely sure that RD2N is any better than regular medical care in the Netherlands. However, reduction of GLmed in the course of time is rare in clinical practice, so the substantial decline in GLmed in response to RD2N treatment supports the idea that it contributes to better diabetes care.

In conclusion, T2D is commonly considered a chronic progressive disease. Reduction of medication dose is rare in regular clinical care. The present report signifies the potential of RD2N treatment as multicomponent lifestyle intervention to improve T2D in a significant number of patients, particularly in terms of medication use, metabolic control, as well as quality of life. Using a multidisciplinary approach, focusing on a broad spectrum of lifestyle skills rather than health literacy alone, as well as provision of biofeedback information on the effects of the intervention seems a viable approach.
Author affiliations

${ }^{1}$ Louis Bolk Instituut, Department of Nutrition and Health, Bunnik, The Netherlands ${ }^{2}$ King's College London Division of Diabetes and Nutritional Sciences, London, UK ${ }^{3}$ General Practitioner, Amsterdam, The Netherlands

${ }^{4}$ Leids Universitair Medisch Centrum, Leiden, Zuid-Holland, The Netherlands

Acknowledgements We are indebted to the participants of the 'Reverse Diabetes2 Now' programme. We thank the whole Reverse Diabetes2 Now team for executing the programme. Furthermore, we thank Lotte Schaffer for her help in data collection. We thank Nicole de Groot, Marianne de Visser, Connie Hoek, Dan Hoevenaars, Barbara Kerstens, Peter Klosse, Ronald Rier, Lotte Schaffer, Martijn van Beek, Albert van der Velde, Maaike de Vries and Renger Witkamp for their contributions to the programme. We thank Klaas Berkhof for his support to this project.

Contributors GKP analysed the data, drafted and revised the manuscript; MB-F designed the study, collected, collated and analysed the data and revised the manuscript; ONP collected data and revised the manuscript; NvdZ was responsible for the medical coordination of the intervention and revised the manuscript. HP is chief medical advisor of Voeding Leeft, and provided scientific input to design of the study and manuscript; PV co-designed the lifestyle intervention and the study, revised the manuscript and is responsible for the overall content of the manuscript (guarantor).

Funding This work was supported by Ekhaga (application number 2017-55) and by VGZ Health Insurance via the foundation Voeding Leeft.

Competing interests None declared.

Patient consent for publication Not required.

Ethics approval The Medical Ethical Reviewing Committee of Wageningen University (NL) reviewed the study protocol and is of the opinion that it does not fall within the remit of the Dutch 'Medical Research Involving Human Subjects Act' (17 January 2019).

Provenance and peer review Not commissioned; externally peer reviewed.

Data availability statement Data may be obtained from a third party and are not publicly available. Data may be obtained from a third party (Foundation Voeding Leeft) and are not publicly available.

Open access This is an open access article distributed in accordance with the Creative Commons Attribution Non Commercial (CC BY-NC 4.0) license, which permits others to distribute, remix, adapt, build upon this work non-commercially, and license their derivative works on different terms, provided the original work is properly cited, appropriate credit is given, any changes made indicated, and the use is non-commercial. See: http://creativecommons.org/licenses/by-nc/4.0/.

\section{ORCID iD}

Gerda K Pot http://orcid.org/0000-0002-0863-4484

\section{REFERENCES}

1 Taylor R. Type 2 diabetes: etiology and reversibility. Diabetes Care 2013;36:1047-55.

2 Ajala O, English P, Pinkney J. Systematic review and meta-analysis of different dietary approaches to the management of type 2 diabetes. Am J Clin Nutr 2013;97:505-16.

3 Bassuk SS, Manson JE. Lifestyle and risk of cardiovascular disease and type 2 diabetes in women: a review of the epidemiologic evidence. Am J Lifestyle Med 2008;2:191-213.

4 Ford ES, Bergmann MM, Kröger J, et al. Healthy living is the best revenge. Arch Intern Med 2009;169:1355.

5 Colpani V, Baena CP, Jaspers L, et al. Lifestyle factors, cardiovascular disease and all-cause mortality in middle-aged and elderly women: a systematic review and meta-analysis. Eur $J$ Epidemiol 2018;33:831-45.

6 Loef $\mathrm{M}$, Walach $\mathrm{H}$. The combined effects of healthy lifestyle behaviors on all cause mortality: a systematic review and metaanalysis. Prev Med 2012;55:163-70.

7 Kvaavik E, Batty GD, Ursin G, et al. Influence of individual and combined health behaviors on total and cause-specific mortality in men and women: the United Kingdom health and lifestyle survey. Arch Intern Med 2010;170:711.

8 Lean ME, Leslie WS, Barnes AC, et al. Primary care-led weight management for remission of type 2 diabetes (direct): an open-label, cluster-randomised trial. Lancet 2018;391:541-51. 
9 Lean MEJ, Leslie WS, Barnes AC, et al. Durability of a primary care-led weight-management intervention for remission of type 2 diabetes: 2-year results of the direct open-label, cluster-randomised trial. Lancet Diabetes Endocrinol 2019;7:344-55.

10 Hallberg SJ, McKenzie AL, Williams PT, et al. Effectiveness and Safety of a Novel Care Model for the Management of Type 2 Diabetes at 1 Year: An Open-Label, Non-Randomized, Controlled Study. Diabetes Ther 2018;9:583-612.

11 Athinarayanan SJ, Adams RN, Hallberg SJ, et al. Long-Term effects of a novel continuous remote care intervention including nutritional ketosis for the management of type 2 diabetes: a 2-year Nonrandomized clinical trial. Front Endocrinol 2019;10:348

12 Look AHEAD Research Group, Wing RR. Long-Term effects of a lifestyle intervention on weight and cardiovascular risk factors in individuals with type 2 diabetes mellitus: four-year results of the look ahead trial. Arch Intern Med 2010;170:1566-75.

13 Wolf AM, Conaway MR, Crowther JQ, et al. Translating lifestyle intervention to practice in obese patients with type 2 diabetes: improving control with activity and nutrition (ICAN) study. Diabetes Care 2004;27:1570-6.

14 Di Onofrio V, Gallé F, Di Dio M, et al. Effects of nutrition motivational intervention in patients affected by type 2 diabetes mellitus: a longitudinal study in Naples, South Italy. BMC Public Health 2018;18:1181.

15 Egger GJ, Binns AF, Rossner SR. The emergence of "lifestyle medicine" as a structured approach for management of chronic disease. Med J Aust 2009;190:143-5.

16 Castelnuovo G, Pietrabissa G, Manzoni GM, et al. Cognitive behavioral therapy to aid weight loss in obese patients: current perspectives. Psychol Res Behav Manag 2017;10:165-73.

17 Pot GK, Battjes-Fries MCE, Patijn ON, et al. Nutrition and lifestyle intervention in type 2 diabetes: pilot study in the Netherlands showing improved glucose control and reduction in glucose lowering medication. BMJNPH 2019;2:43-50.
18 Ajala O, English P, Pinkney J. Systematic review and meta-analysis of different dietary approaches to the management of type 2 diabetes. Am J Clin Nutr 2013;97:505-16.

19 Greaves CJ, Sheppard KE, Abraham C, et al. Systematic review of reviews of intervention components associated with increased effectiveness in dietary and physical activity interventions. BMC Public Health 2011;11:119.

20 Lim S, Kang SM, Kim KM, et al. Multifactorial intervention in diabetes care using real-time monitoring and tailored feedback in type 2 diabetes. Acta Diabetol 2016;53:189-98.

21 Rutten G, De Grauw W, Nijpels G, et al. NHG-Standaard diabetes mellitus type 2 | NHG. Huisarts Wet 2013;56:512-25.

22 Vercoulen JH, Alberts M, Bleijenberg G, et al. De checklist individuele spankracht (cis). Gedragstherapie 1999;32:6.

23 Zhang Y, Pan X-F, Chen J, et al. Combined lifestyle factors and risk of incident type 2 diabetes and prognosis among individuals with type 2 diabetes: a systematic review and meta-analysis of prospective cohort studies. Diabetologia 2020;63:21-33.

$24 \mathrm{Hu}$ FB. Globalization of diabetes: the role of diet, lifestyle, and genes. Diabetes Care 2011;34:1249-57.

25 Shan Z, Ma H, Xie M, et al. Sleep duration and risk of type 2 diabetes: a meta-analysis of prospective studies. Diabetes Care 2015;38:529-37.

26 Hackett RA, Steptoe A. Type 2 diabetes mellitus and psychological stress - a modifiable risk factor. Nat Rev Endocrinol 2017:13:547-60.

27 Zeevi D, Korem T, Zmora N, et al. Personalized nutrition by prediction of glycemic responses. Cell 2015;163:1079-94.

28 Osler ME, Fritz T, Caidahl K, et al. Changes in gene expression in responders and nonresponders to a low-intensity walking intervention. Diabetes Care 2015;38:1154-60.

29 Hill $A B$. The environment and disease: association or causation? Proc R Soc Med 1965;58:295-300. 